Supplement of Atmos. Chem. Phys., 15, 595-615, 2015

http://www.atmos-chem-phys.net/15/595/2015/

doi:10.5194/acp-15-595-2015-supplement

(C) Author(s) 2015. CC Attribution 3.0 License.

(c) (1)

Atmospheric

Chemistry

and Physics

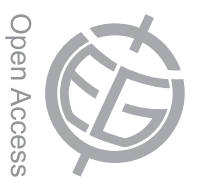

Supplement of

\title{
Multiday production of condensing organic aerosol mass in urban and forest outflow
}

\section{J. Lee-Taylor et al.}

Correspondence to: J. Lee-Taylor (julial@ucar.edu) 

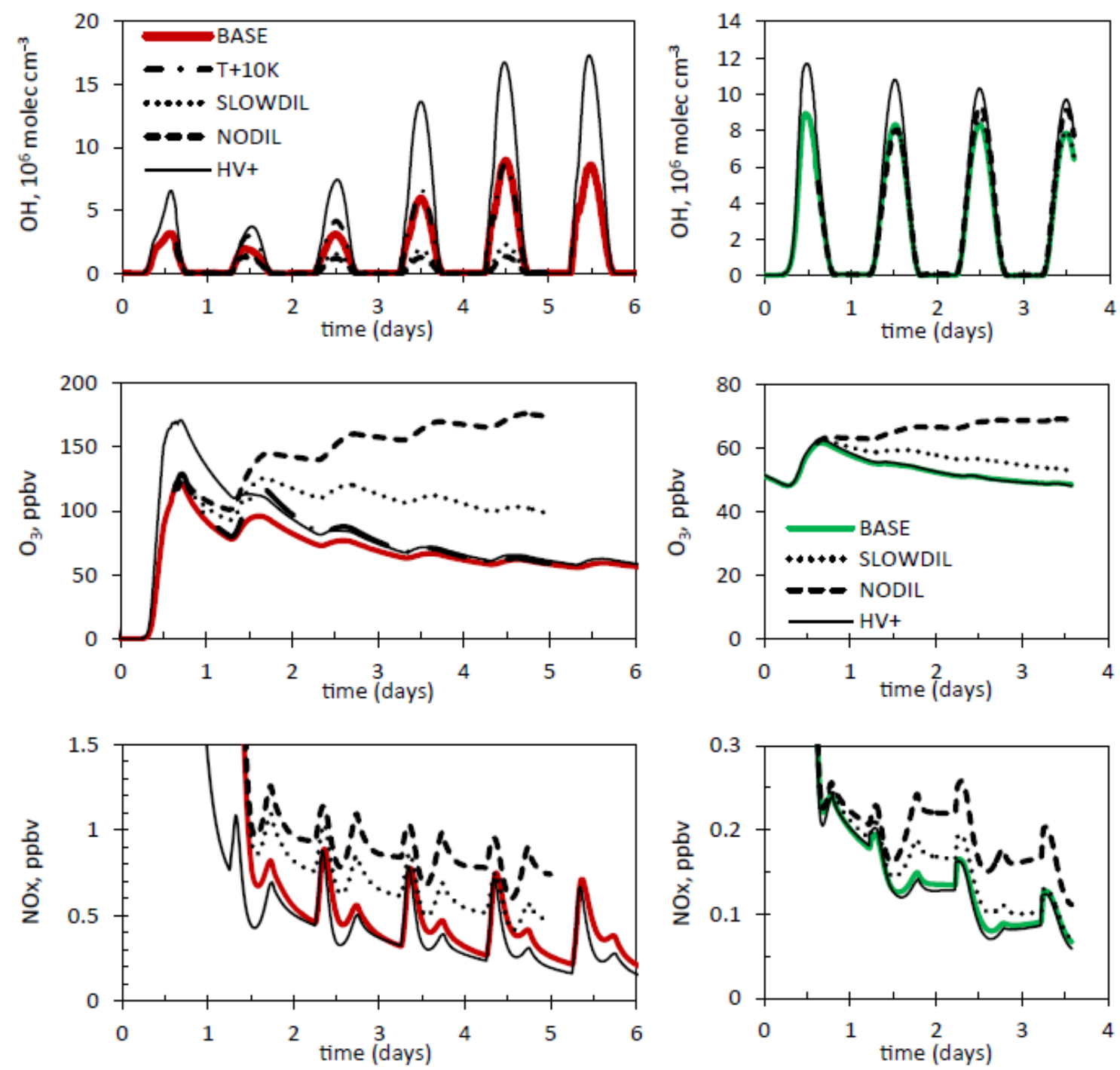

2

3 Figure S1.Timeseries of major oxidants. Left panels show the urban scenario, right panels show the

4 forest scenario. All panels show the reference case and sensitivity cases SLOWDIL, NODIL and HV+.

5 Left panels also show case $T+10 K$. 